\title{
PUEBLOS INDÍGENAS Y CONSTITUCIONALISMO: DE LA IGUALDAD MULTICULTURAL AL DIÁLOGO ENTRE IGUALES(*)
}

\author{
NDIGENOUS PEOPLES AND CONSTITUTIONALISM: FROM THE \\ MULTICULTURAL EQUALITY TOWARDS DIALOGUE BETWEEN \\ EQUALS
}

\section{Marco Aparicio Wilhelmi $(* *)$}

Resumen: El reconocimiento de la pluralidad cultural no ha conllevado la superación de la disociación entre la realidad formal (un Estado nacional basado en una sociedad homogénea) y fáctica (una sociedad pluricultural y un pluralismo político y jurídico). No ha alterado las bases del pacto jurídico-político del constitucionalismo liberal, de raíz monocultural. El argumento de lo jurídico asume ahora la función homogeneizadora que anteriormente cumplian las ideas de desarrollo y cultura nacional.

Esta realidad negativa es retada por la Declaración sobre Derechos de los Pueblos Indigenas de Naciones Unidas (NNUU) de 2007 que reconoce a la libre determinación como prerrequisito de cualquier derecho individual o colectivo y resalta la importancia que la libertad y dignidad de los pueblos tienen con respecto a la libertad y la dignidad de las personas. Este articulo propone un cambio de de paradigma constitucional que permita transitar hacia un modelo constitucional dialógico, hacia un auténtico reconocimiento de la igualdad entre las culturas, por el que los distintos poderes queden obligados a garantizar unas condiciones equitativas de participación en el diálogo entre las culturas (interculturalidad).

(*) El presente trabajo se inserta en el proyecto de investigación "Los derechos de los pueblos indigenas en América Latina. Un estudio interdisciplinar a partir de sus formas de reconocimiento y ejercicio. SEJ2007-61209/JURI",

(**) Profesor de Derecho Constitucional en la Universitat de Girona. Catalunya, España. marco.aparicio@udg.edu. 
Palabras clave: Reconocimiento/ Neoconstitucionalismo/ Declaracion Derechos Indigenas/Interculturalidad.

Abstract: The recognition of cultural plurality has not led to overcoming the dissociation between the formal reality (a national state based on a homogeneous society) and factual reality (a multicultural society and a political and legal pluralism). It has not altered the basis of the legal-political pact of liberal constitutionalism, that has a monocultural root. The legal argument now assumes the homogenizing function previously fulfilled by the ideas of development and national culture.

This negative reality is challenged by the Declaration on the Rights of Indigenous Peoples of the United Nations (UN 2007) which recognizes selfdetermination as a prerequisite of any individual or collective rights, and highlights the importance of the freedom and dignity that of indigenous peoples have regarding freedom and dignity. This article proposes a change of constitutional paradigm that allows moving toward a dialogic constitutional model, towards a genuine recognition of equality between cultures, by which the various powers be obliged to ensure equal conditions of participation in the dialogue between cultures (multiculturalism).

Key words: Recognition/ Neoconstitutionalism / Declaration of Indigenous Rights/Interculturality.

Tabla de Contenido: -1. Igualdad y diversidad. -2. Los límites del constitucionalismo multicultural liberal. $\mathbf{- 3}$. El reconocimiento del derecho a la libre determinación de los pueblos indigenas en la Declaración de Naciones Unidas de 2007. -4. Constitucionalismo dialógico y Estado intercultural: Bolivia como vanguardia.-Referencias. 


\section{Igualdad y diversidad}

"La justicia consiste en igualdad, y así es, pero no para todos, sino para los iguales; y la desigualdad parece ser justa, y lo es, en efecto, pero no para todos, sino para los desiguales" (ARISTÓTELES, 1983). Hoy sabemos que de un modo u otro esta fórmula ha servido de fundamento del constitucionalismo del estado democrático y social. Asi, ante supuestos de desigualdad material entre personas pertenecientes a un determinado colectivo y el resto de la sociedad, esto es, condiciones distintas que dificultan el acceso a los ámbitos de participación política y social, la igualdad real, efectiva, debe permitir, cuando no prescribir, un tratamiento especial encaminado a la superación de la desigualdad de partida. Se trata, como es sabido, de medidas de "discriminación positiva"; medidas correctoras de situaciones de exclusión o subordinación social.

Pues bien, la existencia de pueblos indígenas y su posición en el contexto de los Estados contemporáneos, nos empuja a reclamar una segunda materialización del principio de igualdad, esta vez atendiendo a las diferencias materiales de partida derivadas de las diferencias culturales, no meramente sociales.

Seguramente sería mejor no desconectar esta "segunda materialización" de la primera, la de tipo social. Y ello por diversos motivos. En primer lugar porque, como bien sabemos, la primera, lejos de haber llegado a su realización, está en franco retroceso y sigue siendo la principal promesa incumplida del constitucionalismo contemporáneo. En segundo lugar, porque sería un error, en el que a menudo se incurre, tratar de desvincular los ejes que dan forma a las distintas dinámicas de desigualdad y exclusión que definen a nuestras sociedades. Por el contrario, la mayor parte de los obstáculos a la inclusión son el producto del entrecruzamiento del racismo, el clasismo y la discriminación cultural.

En otras palabras: la materialización de la igualdad no puede quedarse en el terreno de las diferencias sociales sino que debe incorporar, también y de manera entrelazada, las diferencias culturales, que, al igual que las sociales, son elementos que impiden la participación igual de todas las personas.

Desde esta perspectiva, y teniendo en cuenta la dimensión colectiva del hecho cultural, el primer paso a dar consistiría en abandonar la exclusiva centralidad de los derechos (individuales) para atender al protagonismo del reconocimiento efectivo de los sujetos de los derechos. De ahí, como consecuencia, desembocariamos en el terreno de los derechos colectivos. El reconocimiento del sujeto supone introducir un elemento de realidad en un mundo ficticio, el del orden jurídico homogéneo que ahoga la existencia colectiva de las personas en el mar de la igualdad formal. En efecto, frente a la simulación de la homogeneidad cultural y nacional, 
emerge una realidad de distintos sujetos colectivos, cuyas relaciones de convivencia exigen superar el viejo esquema del Estado-nación, basado en la pétrea identificación entre pueblo, nación y Estado.

La imposibilidad de seguir negando la presencia en una misma realidad estatal de pueblos diversos, de distintas culturas, y el rechazo a la supremacía y, por tanto, del dominio, de unos sobre otros, ha de llevarnos a poder concebir una organización política basada en el co-gobierno, a partir de instituciones comunes pero también desde el respeto y la articulación de las diferencias. Sujetos que en su libre determinación opten por conformar un espacio común de convivencia, respetuoso de sus identidades pero a la vez capaz de generar un espacio compartido a partir de un diálogo intercultural entre iguales, fundamento de la legitimidad de los poderes.

\section{Los límites del constitucionalismo multicultural liberal}

Si algo puede concluirse del proceso de reformas constitucionales de orden "multicultural" emprendido en América Latina en los últimos tiempos y, al menos, hasta la Constitución boliviana de 2009, es que no se ha logrado alcanzar el escenario de co-gobierno recién apuntado. A lo sumo, se ha transitado de la simple y llana negación de la diversidad cultural a su incorporación en tanto que "riqueza" a preservar, esto es, más en términos descriptivos que prescriptivos y con el límite de la no alteración de las bases esenciales del pacto juridico-politico del constitucionalismo liberal, de raiz monocultural.

Entre 1987 y 2001 la mayor parte de paises latinoamericanos emprendieron el camino de lo que se ha denominado "constitucionalismo multicultural" (VAN COTT, 2002). Así es: la práctica totalidad de textos constitucionales hoy vigentes han incorporado referencias al carácter multicultural o multiétnico de la "sociedad nacional", y reconocimientos más o menos amplios de derechos especiales para los integrantes de los pueblos indígenas. Ahora bien, el reconocimiento de la pluralidad no ha conllevado una reforma pluralista de la organización institucional y de los modos de producción jurídica quedando lejos la superación de la disociación entre la realidad formal (un Estado nacional basado en una sociedad homogénea) y fáctica (una sociedad pluricultural y un pluralismo político y jurídico). Como indica Clavero, "el constitucionalismo conocido y acreditado, pretendiendo que se debe a derechos de ecuación ciudadana y predicación universal dentro de cada frontera de Estado, a lo que responde estructuralmente es al monismo cultural de la antropología-ficción" (CLAVERO, 2006:130).

En efecto, es común a los textos constitucionales hoy vigentes que el reconocimiento de la presencia de los pueblos o comunidades indigenas, alli donde se realiza, no comporte en rigor el aseguramiento normativo de una determinada

posición jurídica, de unos determinados derechos colectivos. Hay reconocimiento de 
la existencia indígena y de su peculiar identidad, pero la efectividad de los derechos anunciados depende casi íntegramente de una posterior creación normativa de instituciones estatales de orden monocultural. No existen, en consecuencia, auténticos derechos constitucionales colectivos.

Asi se demuestra en el conjunto de planteamientos constitucionales al respecto: prácticamente todos ellos parten de algún tipo de declaración general de reconocimiento de la pluralidad cultural o étnica (con distintas fórmulas: "reconocer la preexistencia étnica y cultural de los pueblos indígenas argentinos", "El Estado reconoce y protege la diversidad étnica y cultural de la Nación Colombiana", "La Nación mexicana tiene una composición pluricultural...", etc.), pero tales declaraciones empiezan a debilitarse ya en el mismo texto constitucional. Incluso en aquellas Constituciones que de manera más decidida abordan el reconocimiento de derechos indigenas, aparecen diversos frenos a un efectivo reconocimiento de la pluralidad: en primer lugar, es frecuente la subordinación al desarrollo legislativo del conjunto de los derechos reconocidos; en segundo lugar, destaca la ausencia de correlación entre tales derechos y el resto del articulado constitucional, que permanece de espaldas a la pluralidad política y jurídica realmente existente. En tercer lugar, todos los textos optan por un reconocimiento débil, subordinado, del Derecho propio de los pueblos indigenas y del alcance de su jurisdicción. En cuarto y último término, se incluyen siempre una "cláusula de freno" al reconocimiento de los derechos indigenas: en todos los textos constitucionales, se incorporan previsiones que delimitan el alcance de los derechos indigenas reconocidos mediante el principio de no contradicción con "los derechos y libertades reconocidos en la Constitución", "los derechos humanos" o incluso en algunos casos, una referencia genérica a "la Constitución y la Leyes" que pone en cuestión la constitucionalidad misma de los derechos indigenas reconocidos.

En resumen: los derechos colectivos indigenas no son reconocidos como auténticos derechos subjetivos sino que se articulan como concesión del poder político al ejercicio de un cierto grado de autonomia grupal, basada en el respeto de determinadas manifestaciones de la propia cultura (idioma, costumbres, tradiciones o formas de organización social, etc. a menudo configuradas semánticamente como "derechos") siempre sometidas a la cláusula de no contradicción con los derechos individuales nacional e internacionalmente reconocidos (Derechos Humanos).

Con ello, el desarrollo de las manifestaciones de la identidad indígena (manifestaciones culturales o "derechos colectivos"), aun aceptándose en cierta medida, queda supeditado al respeto de un determinado marco jurídico que, dada la estructura socio-politica existente, responde a los principios de una única cultura, la cultura dominante. El argumento de lo jurídico (especialmente Constitución y derechos individuales) asume la función homogeneizadora que anteriormente cumplian las ideas de desarrollo y cultura nacional. 
De este modo, el principio de igualdad juridica formal sigue erigiéndose, de modo constante desde los tiempos de la formación de los Estados nacionales en Latinoamérica, en principal instrumento de un Derecho, el estatal, considerado como instancia neutra (haciendo caso omiso de la relación de fuerzas subyacentes) que delimita el espacio pluricultural de convivencia. Esa pretendida neutralidad es tributaria del concepto racional de Constitución con base al cual los principios incorporados por ella responderían a criterios universales fruto de la razón (universal, objetiva). A su vez, parte de una cultura constitucional que concibe la estructura jurídica sobre la base de la separación entre dos grandes polos: el Estado y el individuo. En tal contexto, los únicos derechos subjetivos son los individuales, que se configuran como elementos de referencia previos, como datos objetivos, que la Constitución debe reconocer junto con una serie de poderes cuya legitimidad estriba en ofrecerles protección.

Sólo el Estado, y siempre justificado en la propia conveniencia de los individuos, puede representar intereses colectivos que, en ciertas ocasiones, pueden llegar a limitar de algún modo los derechos de las personas; por esta razón, los derechos colectivos de los pueblos indígenas, en el caso de ser establecidos constitucionalmente, no se articulan como derechos subjetivos, previos a la idea de Estado y poseedores de un haz de facultades intangibles y directamente exigibles, sino como concesiones de éste y sujetos a la normativa estatal.

La mencionada debilidad y escasa ejecutividad de los derechos indigenas reconocidos se ha venido constatando en los últimos, además, ante el avance de las regulaciones en materia de libre comercio y medio ambiente, muy condicionadas por una normativa internacional en general ajena al respeto de los derechos indígenas en materia de acceso y control de recursos, biodiversidad o propiedad intelectual.

Se constata, en definitiva, un sentimiento generalizado de limitada eficacia de los instrumentos jurídicos en vigor, siendo frecuentes las denuncias por la ausencia de implementación en la normativa de desarrollo y en la puesta en marcha de políticas públicas concretas y efectivas. Las conclusiones recién apuntadas han llevado a más de un autor a señalar, sin desmerecer la importancia de los cambios constitucionales en la materia, que "todo indica que se terminó el periodo de avances en el reconocimiento de derechos de los pueblos indígenas y reformas blandas en América Latina. Tales procesos formaron parte de los ajustes institucionales, coyunturas constitucionales o aperturas y pactos..."(TOLEDO, 2005:6).

\section{El reconocimiento del derecho a la libre determinación de los pueblos indígenas en la Declaración de Naciones Unidas de 2007}

En el plano juridico internacional la experiencia ha arrojado resultados contradictorios. Pese a los evidentes avances cosechados en los últimos tiempos ha 
habido que enfrentar no sólo las dificultades estructurales del propio sistema internacional de derechos humanos, sino también los obstáculos que los pueblos indigenas, tradicionalmente excluidos del terreno del debate político-institucional, han encontrado a la hora de conseguir algún tipo de implementación de las decisiones de los órganos internacionales de derechos humanos, cuando éstas se han dado.

El propio Alto Comisionado de Naciones Unidas para los Derechos Humanos, en su evaluación del Decenio de los derechos de los pueblos indigenas (1994-2004), concluyó que "con respecto a los pueblos indigenas, los valores básicos y los principios que son la base de los sistemas legales nacionales e internacionales, no están siendo aplicados en forma justa ni de manera no-discriminatoria. La impunidad por violaciones a los derechos humanos de los pueblos indígenas es tolerada ampliamente" (OFICINA DEL ALTO COMISIONADO PARA LOS DERECHOS HUMANOS, 2004).

Ahora bien, la Declaración sobre Derechos de los Pueblos Indígenas de Naciones Unidas (NNUU) de 2007 supone un hito en el camino por la construcción de espacios igualitarios de convivencia pluricultural. Sin duda, el punto de partida se halla en el reconocimiento del derecho de libre determinación de los pueblos indígenas, realizado en su art. 3: "Los pueblos indigenas tienen derecho a la libre determinación. En virtud de ese derecho determinan libremente su condición politica y persiguen libremente su desarrollo económico, social y cultural".

Este precepto se ve reforzado por las consideraciones preliminares que incorpora la misma Declaración, cuando nos recuerda que la normativa internacional "afirma la importancia fundamental del derecho de todos los pueblos a la libre determinación", y señala que "nada de lo contenido en la presente Declaración podrá utilizarse para negar a ningún pueblo su derecho a la libre determinación, ejercido de conformidad con el derecho internacional".

La importancia de que, finalmente, y tras más de veinte años de trabajos y negociaciones, se haya aprobado la Declaración con este precepto, es indudable. En primer lugar, porque la Declaración representa, incluso desde antes de su aprobación definitiva, un hito no sólo político, sino también jurídico de grandes dimensiones. Y lo es tanto en términos generales, por lo que respecta a la plasmación de derechos colectivos que irrumpen con fuerza en el universo del derecho internacional de los derechos humanos, como en el más estricto ámbito de los derechos de los pueblos indígenas y de sulibre determinación.

En segundo término, porque, como puede comprobarse, el artículo tercero consiste en una mimética traslación, con la mera adición del adjetivo "indígenas", del primer artículo de los dos principales instrumentos de Naciones Unidas en materia de 
Derechos Humanos: Ios Pactos de Derechos Civiles y Políticos (PIDCP) y de Derechos Económicos, Sociales y Culturales (PIDESC), ambos de 1966.

Y dicha traslación no debe considerarse como un mero efecto reflejo, una manera de conceder en el plano declarativo lo que se prevé para el conjunto de los pueblos en el terreno de los mencionados instrumentos jurídicos, vinculantes. Muy al contrario: se trata, nada más y nada menos, de una reformulación radical del eterno debate sobre el alcance del derecho de libre determinación de los pueblos que tan contundentemente se quiso zanjar con la famosa doctrina del "agua azul" o "agua salada" (blue water).

Merece la pena recordar el debate: el origen del reconocimiento explícito del derecho de libre determinación en el sistema de NNUU se encuentra ya en la propia Carta de fundación de las NNUU, cuyo art. 1.2 establece como objetivo "fomentar entre las naciones relaciones de amistad basadas en el respeto al principio de igualdad de derechos y al de la libre determinación de los pueblos, y tomar otras medidas adecuadas para fortalecer la paz universal".

La Declaración sobre la concesión de la independencia a los países y pueblos coloniales (1960) enuncia que "todos los pueblos tienen derecho a la libre determinación; en virtud de este derecho, determinan libremente su estatuto politico y buscan libremente su desarrollo económico, social y cultural", entendiendo, además, que "Ia sujeción de pueblos a una subyugación, dominación y explotación extranjera" debe ser considerada como "una denegación de los derechos humanos fundamentales"(1).

Salta a la vista la carga, la potencialidad de la previsión, y de ahí la extrema importancia de que fuera recogida tal cual como artículo primero tanto del PIDESC como del PIDCP. Con ello, se sitúa en el pórtico del reconocimiento internacional de los derechos humanos universales, es decir, se erige, si quiera simbólicamente, como prerrequisito de cualquier derecho individual o colectivo y se resalta la importancia que la libertad y dignidad de los pueblos tienen con respecto a la libertad y la dignidad de las personas.

Como es sabido, tal disposición fue objetada enseguida por algunos Estados que trataron de establecer barreras protectoras a su integridad territorial. Asi, desde el mismo 1960, la Declaración sobre la independencia a los países y pueblos colonizados, previó expresamente que la integración y la libre asociación con los 
Estados ya constituidos sean vias a través de las cuales los pueblos puedan ejercer su derecho a la libre determinación.

Por su parte, la Declaración sobre los Principios de Derecho Internacional referentes a las Relaciones de Amistad y Cooperación entre los Estados conforme a la Carta de NNUU (1970), se encargó de acotar el derecho de libre determinación estipulando que todo Estado soberano e independiente, dotado de un gobierno que represente al conjunto de su población, debía ser considerado como un Estado que se conduce en conformidad al principio de igualdad de derechos y del derecho de los pueblos a disponer de sí mismos, en lo que concierne a esa población. Por si quedaran dudas, la misma Declaración señala además que no podrá deducirse de sus previsiones que se autoriza o alienta cualquier acción que pudiera amenazar, totalmente o en parte, la integridad territorial o la unidad política de dichos estados. Esta declaración precisa, además, que sólo cuando todas los medios pacíficos de alcanzar la libre determinación hayan fracasado, se podrán adoptar otras acciones.

Muchos autores, casi tantos como actores gubernamentales, quisieron ver en esta última Declaración la formalización definitiva de la doctrina del "agua azul" o "agua salada" (blue water). Como es sabido, en virtud de la misma se limitaría la aplicabilidad del derecho a los supuestos en que entre el Estado opresor y el pueblo oprimido mediara un espacio marítimo con lo que se reduce a los supuestos de colonialismo transoceánico. De este modo, una vez ejercida por las colonias, la libre determinación cambiaría de naturaleza y pasaría a referirse más bien a la capacidad que los nuevos Estados independientes tendrian para oponerse a cualquier intento de involución del proceso por acción de las potencias coloniales o de intención de quiebra de su integridad territorial por parte de los pueblos que se hallan integrados en esa realidad estatal; es decir, de ser un derecho de los pueblos, se convertiría en un derecho de Estados ya constituidos a su propia integridad territorial, la cual es declarada absolutamente inviolable(2).

Con ello, los pueblos indigenas no entrarian en ese ámbito, consolidándose la consideración de los y de las indigenas como integrantes de la nación que el Estado representa, como ciudadanos y ciudadanas del nuevo Estado que comienza su andadura, una andadura que requerirá precisamente la construcción de una identidad nacional fuerte y homogénea, fundamentada a partir de la negación de las diferencias.

(2) Concretamente, esa es la idea que recoge la Declaración sabre to Concesión de lo Independencia o los Poises Y Pueblos Coloniafes de 14 de diciembre de 1960, al establecer en su art. 6 que "Todo intento encaminado a cuebrantar total o parcialmente la unidad nacional y la integridad territorial de un pais es incompatible con los propósitos y principios de la Carta de las Naciones Unidas". Precepto que no hace mas que introducir ambiguedad y confusión ya que comparte texto con el art. 2 de la misma Declaración, en el que se reconoce de manera, en principio clara, que "Todos los pueblos tienen el derecho a la libre determinación; en virtud de este derecho, determinan libremente su concición politica y persiguen sbremente su desarrollo económico, social ycultural", Asamblea General, Resol. 1514 (xV) 
De este modo, pese a que el derecho que tratamos se haya reafirmado posteriormente en otros textos(3), los temores de los Estados al cuestionamiento de su integridad territorial y de la unidad del poder que representan han llevado a la hegemonia de una doctrina pensada para impedir el reconocimiento de la libre determinación por parte de NNUU a los pueblos indigenas(4). Tras el paréntesis descolonizador, la idea de pueblo vuelve a identificarse con los Estados constituidos (la población de los mismos), sin que quede lugar alguno para los pueblos que no constituyan Estados; sin espacio para la desvinculación conceptual entre las categorías de puebloy Estado.

Pues bien, la Declaración de Naciones Unidas sobre Derechos de los Pueblos Indigenas, al partir en idénticos términos que el PIDCP y el PIDESC del derecho de libre determinación de los pueblos (indigenas) da un vuelco radical a la situación, partiendo, como señala el mismo Preámbulo, del principio de la igualdad entre todos los pueblos, pues la Declaración arranca afirmando que: "...los pueblos indigenas son iguales a todos los demás pueblos y reconociendo al mismo tiempo el derecho de todos los pueblos a ser diferentes, a considerarse a si mismos diferentes y a ser respetados comotales..."

A partir de ahi, es necesario volver a leer el art. 1 de los pactos internacionales mencionados para empezar a levantar las barreras que han querido impedir que el mismo abarque a todos los pueblos, considerados iguales en derechos. Con ello, se reivindica con fuerza la libre determinación de los pueblos como prerrequisito o precondición del respeto del conjunto de derechos de los integrantes de tales pueblos.

En eso, nada más y nada menos, consiste el avance que la Declaración conlleva en cuanto al derecho de libre determinación de los pueblos se refiere: ayudar

(3) Como el Acta final de Helsinki de la Conferencia sobte la seguridad y la cooperación en Europa (1975), o más recientemente, la Declaración de Viena de la Conferencia Mundial de derechos humanos (1993). En la primera se enuncia que "los Estados participantes respetarán la igualdad de dereches de los pueblos y derecho de los pueblos a disponer de si mismos, de actuar en todo momento en conformidad con los objetwos y principios de la Carta de Naciones Unidas y a las normas de derecho inter nacional pertinentes incluidas las relacionadas con la integridad territorial de los Estados". En la Declaracion de Viena, por su parte, se establece expresamente que "todos los pueblos tienen el derecho de disponer de si mismos. En virtud de ese derecho, ellos determinan libremente sus estatus politicas y buscan libremente su desarrollo económico, social y cultural".

(4) Por otra parte, la carga politica de las interoretaciones que NNuU ha realizado sobre el alcance del derecho es más que evidente. Asi, se ha demostrado un cambio radical de perspectiva en función de si el derecho de autodeterminación se ejerce en el proceso de liberación colonial o si se trata de movimientos de independencia en el interior de Estados surgidos de la descolonización. La Asamblea General de las NNUU aprobó en 1960 el derecho de autodeterminación de la colonia de Nigeria contra Gran Bretaȟa, pero se opuso tenazmente en 1960 cuando el pueblo de los Ibos intentó ejercer su derecho de autodeterminación contra el Gobierno Federal de Nigeria creando el estado independiente de Biafra. Aunque también contamos con algún ejemplo aislado de una interpretación contraria: cuando el pueblo bengali se alzó en armas contra Pakistán con la ayuda de la india obteniendo su independencia, la Asamblea General no tuvo inconvenientes en aceptar en su seno en el ax̌o 1974 a i nuevo Estado, aun cuando tampoco se trataba de una ex colonia y la integridad territorial de Pakistán quedaba seriamente afectada. 
a quitarle el corsé de la explicación histórica ligada al proceso de descolonización para reivindicar que las condiciones de dominación, y consiguiente exclusión y desigualdad, de unos colectivos sobre otros sigue hoy vigente al interior de los Estados que se conformaron. En otras palabras: la Declaración actualiza y refuerza la comprensión de los derechos humanos a partir de la relación entre lo colectivo y lo individual reafirmando que mientras se den situaciones de dominación de unos pueblos sobre otros, la vigencia de los derechos, tanto colectivos e individuales, se hallará en permanente y grave cuestionamiento.

A la vista de estas consideraciones, no nos debería resultar extraño que, como es bien sabido, uno de los elementos que mayores tensiones y obstáculos ha generado en el proceso de aprobación de la Declaración haya sido el relativo a la consagración del derecho de autodeterminación de los pueblos indigenas. Como tampoco nos debe sorprender que la representación indígena lo haya venido planteando como una de las demandas principales, como núcleo alrededor del cual se debía articular toda la Declaración. En contraposición, desde distintos gobiernos se ha mostrado, y se sigue mostrando, un rechazo sistemático al derecho de libre determinación.

La rígida postura demostrada por buena parte de la representación gubernamental en los debates, contrasta con la ofrecida por la mayoría de las representantes y los representantes indígenas, quienes han apostado por una visión abierta y más bien funcional de la idea de autodeterminación. De lo que se trata, sostienen, es principalmente de asegurar el control de las propias instituciones sociales, politicas y culturales, territorios y recursos y un esquema de relaciones con la estructura estatal, basado en el consentimiento y la participación.

La propia Declaración ha acabado recogiendo en su preámbulo dicho propósito cuando señala que la Asamblea General está "convencida de que el reconocimiento de los derechos de los pueblos indigenas en la presente Declaración fomentará relaciones armoniosas y de cooperación entre los Estados y los pueblos indigenas, basadas en los principios de la justicia, la democracia, el respeto de los derechos humanos, la no discriminación y la buena fe...".

En otras palabras: se pretende un reconocimiento en tanto que sujetos, $y$ no objeto de regulaciones; una subjetivización colectiva como primer paso para la superación de esquemas de relación con las sociedades dominantes y su aparato institucional que han pasado por fases que van desde las distintas dinámicas de aniquilación, de exclusión, de olvido y de asimilación, hasta las más contemporáneas propuestas de integración subordinada con matices de respeto identitario.

Aun así, algunos representantes gubernamentales, fundamentalmente de Estados Unidos de América (EEUU), Nueva Zelanda y Australia, secundados por 
algunos países del continente africano como Nigeria, Namibia y Botswana, han insistido hasta la saciedad en la necesidad de limitar el alcance de la libre determinación mediante la salvaguarda de la "unidad política" y la "integridad territorial". Se trataría de recoger, en otros términos, la fórmula ya ensayada en el Convenio núm. 169 de la Organización Internacional del Trabajo (OIT)(5).

Y dicha cerrazón sorprende especialmente por el hecho de que el texto, en su conjunto, ya incorporaba desde los primeros debates una serie de previsiones que precisamente tienen por objeto limitar la idea de autodeterminación (y con ello, también la propia idea de pueblo indígena) para llevarla al estricto ámbito de sus manifestaciones internas.

El art. 4, establece lo siguiente: "Los pueblos indigenas tienen derecho a conservar y reforzar sus propias instituciones politicas, jurídicas, económicas, sociales y culturales, manteniendo a la vez sus derechos a participar plenamente, si lo desean, en la vida política, económica, social y cultural del Estado."

Los pueblos indigenas, al parecer, podrán decidir hasta qué punto participan en la vida del Estado. Detrás de esta aparente actitud respetuosa, lo que se halla es una concepción restringida de la idea de pueblo cuando se trata de un pueblo indígena. Puede parecer que el legislador esté pensando como objeto de regulación en pequeñas comunidades más o menos aisladas, en minorías antes que en pueblos, porque sino difícilmente se podría entender esa autoexclusión de los ámbitos de toma de decisiones del Estado. ¿Se puede pretender dicha separación en realidades como las que se viven en Guatemala, Ecuador, Bolivia o incluso en Panamá donde la presencia indigena es menor? La respuesta sólo puede ser positiva si se hace desde la consideración de las comunidades por separado y no realmente desde los pueblos indigenas, entendidos desde su integridad.

El art. 4 nos ofrece más argumentos en este sentido al añadir que: "...los pueblos indigenas, en ejercicio de su derecho de libre determinacion, tienen derecho a la autonomía o el autogobierno en las cuestiones relacionadas con sus asuntos internos y locales, asi como los medios para financiar sus funciones autónomas."

(5) El Convenio nưm. 169 CIT es el texto que hasta la fecha constituye el ûnico instrumento juridico internacional en la materia que se refiere a los derechos de los "Pueblos Indigenas". Pero frente a un reconocimiento amplio del sujeto, el Convenio opta por precisar que "la utilización del término pueblos en este Comvenio no deberá interpretarse en el sentida de que tenga implicaciōn alguna en lo que atañe a los derechos que pueda conferirse a dicho término en el derecho internacional" (art 1). Con ello, la OIT preteride zanjar la espinosa cuestión del reconocimiento internacional del derecho de autodeterminación de los pueblos. 
De manera inmediata tras su enunciado se precisa un ejercicio concreto del derecho de libre determinación: el de la autonomia para los asuntos internos y locales. El problema es que ninguna otra forma especifica de ejercicio se anuncia en la Declaración, no existe ninguna referencia a "otras formas", a otras manifestaciones.

En la misma línea de defensa de la estatalidad ya conformada se pronuncia el art. 33.1: "Los pueblos indigenas tienen derecho a determinar su propia identidado pertenencia conforme a sus costumbres y tradiciones. Ello no menoscaba el derecho de las personas indigenas a obtener la ciudadania de los Estados en que viven."

Parece que el núcleo informador del texto en su conjunto lo constituye esa concreta forma de autodeterminación, referida a la autonomia dentro del respeto de la existencia e integridad del Estado.

Pese a ello, para no dejar rendija alguna a la entrada de dudas o interpretaciones, los Estados arriba mencionados, firmemente conducidos por los EEUU, condicionaron su voto favorable a la introducción de una cláusula de cierre de una claridad meridiana. El artículo 46.1 definitivamente aprobado precisa que: "Nada de lo señalado en la presente Declaración (...) se entenderá en el sentido de que autoriza o fomenta acción alguna encaminada a quebrantar o menoscabar, total o parcialmente, la integridad territorial o la unidad politica de Estados soberanos e independientes."

Las cautelas y frenos aparecen con nitidez y además no se detienen sólo en una intocable integridad territorial, física, del Estado, sino que se extiende a su unidad política. Se plantea así un peligroso concepto que si no se interpreta como reiteración del concepto de unidad territorial, podría llegar a ser utilizado incluso como freno a formas amplias de autonomia interna de los pueblos indigenas.

\section{Constitucionalismo dialógico y Estado intercultural: Bolivia como vanguardia}

Que el conjunto de reformas constitucionales emprendidas en América Latina no suponen un cambio de paradigma ha sido ya suficientemente constatado. Ahora bien, en tanto que muestras del constitucionalismo garantista, también es cierto que habría que valorarlas como sustanciales avances fundamentalmente por la incorporación al centro del discurso normativo de los sujetos y los derechos colectivos, cuestión que debería quedar fuera de todo debate tras la aprobación de la Declaración sobre los Derechos de los Pueblos Indigenas.

Pero es importante subrayar que en ningún caso se ha llegado a establecer como punto de partida de la regulación constitucional un auténtico principio de igualdad entre las distintas culturas. Ninguno de los Estados que ha reconocido la 
diversidad cultural de sus pueblos ha renunciado a conservar la primacía de una cultura sobre las restantes.

Incluso la Constitución ecuatoriana de 2008 , ejemplo de constitucionalismo garantista, se sitúa en tal posición: pese al alcance del reconocimiento de derechos y de sujetos, los ambiciosos objetivos de transformación social no parece que apunten a un cuestionamiento del patrón monocultural de la institucionalidad y del ordenamiento jurídico.

Porque, en realidad, sólo habrá cambio de paradigma constitucional cuando se den las condiciones para transitar hacia un modelo dialógico, es decir, un constitucionalismo basado en un auténtico reconocimiento de la igualdad entre las culturas. A partir de tal situación, deberían los distintos sujetos colectivos estar en condiciones para entablar un equilibrado diálogo intercultural desde el que paulatinamente se avance en la conformación de unos parámetros axiológicos compartidos.

Ahora bien, debe subrayarse que pluralismo cultural no significa un absoluto pluralismo ético; la igualdad de las culturas se predica respecto de parámetros valorativos que deben converger en la consideración de la dignidad humana como valor superior, como límite de lo decidible. El punto clave está en que, a diferencia de la situación actual, no puede existir un único intérprete, un traductor privilegiado de lo que deba entenderse por "dignidad humana"; el Estado intercultural, dialógico, es el que permite la construcción de un horizonte común de sentidos desde las aproximaciones de las distintas culturas existentes.

El reconocimiento constitucional del fin del paradigma del Estado como manifestación de la unidad jurídica y de poder no desactivará, en sí mismo, las amenazas que se ciernen sobre los derechos y las libertades subjetivas. El pluralismo juridico no es sinónimo de más democracia; todo depende de que se asegure la limitación de todos los centros de poder mediante efectivos, aunque diversos, mecanismos de control y de participación democráticos. Ese es el reto del Estado intercultural, si además de intercultural se pretende social y democrático de Derecho, esto es, constitucional en sentido material. Entre tales mecanismos, el Estado intercultural, necesariamente, debe procurar que los distintos centros de poder actúen de manera no aislada sino interrelacionada, de manera que existan tendencias de recíproco equilibrio en la construcción del espacio común de convivencia.

En efecto, la interculturalidad del Estado conlleva que no baste el reconocimiento de la existencia de múltiples culturas (multiculturalidad), sino que los distintos poderes de dimensión pública queden obligados a garantizar unas condiciones equitativas de participación en el diálogo entre dichas culturas (interculturalidad). Sin la promoción de dichas condiciones, que apuntan también a la 
construcción de identidades inclusivas, se abona el terreno de la dominación de la cultura o culturas hegemónicas sobre las minoritarias, por mucho que estén reconocidas constitucionalmente. $Y$ merece la pena insistir en que, pese a que en ocasiones se quiera presentar de manera distinta, tras la mayor parte de las movilizaciones indigenas $y$ afrodescendientes se halla la voluntad de reformular el pacto de convivencia, no de eliminarlo sin más.

Es pronto para afirmarlo pero seguramente podamos encontrar el germen de lo referido en el proceso constituyente boliviano que aunque ya conozca un primer resultado, la Constitución aprobada en referéndum en 2009 , no se puede decir que se trate de un proceso cerrado. Pese a los importantes recortes que el texto constitucional finalmente aprobado ha experimentado como "peaje" para desencallar el bloqueo en el que se encontraba su aprobación, se trata de un importante paso adelante en el desarrollo de un constitucionalismo verdaderamente pluralista. Su complejidad, y el hecho de que en buena medida el proceso de transformaciones del Estado boliviano esté todavía abierto, impiden que podamos en este texto dedicarle una atención mayor.

Veamos, de manera muy tangencial, el contenido de algunas de sus disposiciones: en su articulo primero se empieza a concretar el propósito marcado en el Preámbulo consistente en refundar Bolivia como Estado Plurinacional, al establecer la forma del Estado en los siguientes términos: "Bolivia se constituye en un Estado Unitario Social de Derecho Plurinacional Comunitario, libre, independiente, soberano, democrático, intercultural, descentralizado y con autonomías. Bolivia se funda en la pluralidad y el pluralismo político, económico, jurídico, cultural y lingüistico, dentro del proceso integrador del pais".

Su artículo segundo precisa cuál es el sustento de la pluralidad prescrita: "Dada la existencia precolonial de las naciones y pueblos indigena originario campesinos y su dominio ancestral sobre sus territorios, se garantiza su libre determinación en el marco de la unidad del Estado, que consiste en su derecho a la autonomia, al autogobierno, a su cultura, al reconocimiento de sus instituciones y a la consolidación de sus entidades territoriales, conforme a esta Constitución y la ley".

Más adelante, en el art. 9.1, se establece entre los fines y funciones esenciales del Estado "constituir una sociedad justa y armoniosa, cimentada en la descolonización, sin discriminación ni explotación, con plena justicia social, para consolidar las identidades plurinacionales".

Uno de los aspectos que han quedado pospuestos más allá de la Constitución ha sido el desarrollo del régimen autonómico que debe acoger el desarrollo de la libre determinación indigena originaria campesina que, en virtud del artículo 289, "consiste en el autogobierno como ejercicio de la libre determinación de las naciones y los 
pueblos indigena originario campesinos, cuya población comparte territorio, cultura, historia, lenguas, y organización o instituciones juridicas, politicas, sociales y económicas propias".

El artículo 290 en su punto segundo señala que "el autogobierno de las autonomias indigenas originario campesinas se ejercerá de acuerdo a sus normas, instituciones, autoridades y procedimientos, conforme a sus atribuciones y competencias, en armonía con la Constitución y la ley" (art. 292). Debemos por tanto esperar al desarrollo de tales previsiones para ver si el proceso constituyente boliviano se frena en la reiteración de la subordinación del orden jurídico y político indígena a la Ley del Estado o si, por el contrario, es capaz de superar los limites del reconocimiento para transitar hacia la amplitud del entendimiento y del diálogo entre iguales.

En casos como el de Bolivia, el verdadero reconocimiento de la pluralidad cultural de la sociedad residiria en emprender procesos de reconocimiento asimétrico y diferenciado de identidades nacionales y étnicas en los distintos planos territoriales: el plano comunitario, el local, el regional y el estatal. Y esa es la propuesta: garantizar, mediante una concepción pactista del poder, la convivencia mediante la articulación de la pluralidad en la unidad política común de una sociedad diversa. Por ello se habla de distintos ámbitos autonómicos en los que aparecerían autonomías regionales por comunidad lingüística y cultural con distintos grados de autogobierno político, dependiendo de la densidad política y extensión de las identidades culturales demandantes (GARCÍA LINERA, 2009).

Como es sabido, tales planteamientos, que finalmente lo que tratan es de poner fin a la ficción de la unidad cultural del Estado, han disparado todas las alarmas del soberanismo etnocéntrico anclado en la obsesión por el monismo político y jurídico, algo que, por otra parte, no sólo afecta a la relación entre pueblos indígenas y Estados, sino que es general, como lo demuestra con intensidad el proceso de integración europea.

Para finalizar, quizás valga la pena insistir en la idea central que se ha querido presentar en este texto: la diversidad cultural representa uno de los retos esenciales de cualquier proyecto político de convivencia que pretenda sustituir las dinámicas de dominación por otras que aseguren una igual inclusión en los procesos democráticos. Frente a la perspectiva liberal dominante y su interpretación del principio de igualdad, resulta necesario cuestionar las bases del modelo hegemónico de participación política y social partiendo del reconocimiento de los sujetos colectivos. 


\section{Referencias}

ARISTÓTELES, (1983). Politica. Ed. de J. Marías y M. Araujo. Madrid: C.E.C.

CLAVERO, B., (2006). "Antropologías normativas y derechos humanos: ¿Multiculturalismo constituyente en el Ecuador?". En Revista Vasca de Administración Pública, N. 74, pp.103-141.

GARCIA LINERA, Á., Autonomias indigenas y Estado multicultural. Una lectura de la descentralización regional a partir de las identidades culturales. Disponible (abril/2009) en: http://www.descentralizacion.org.bo/upload/166_propuesta_garcialinera.pdf

OFICINA DEL ALTO COMISIONADO DE NACIONES UNIDAS PARA LOS DERECHOS HUMANOS, (2004). Evaluación del decenio internacional. Urgente necesidad de renovación de mandato y mejora del proceso de elaboración de normas de Naciones Unidas sobre los Derechos Humanos de los Pueblos Indigenas. Ginebra-Nueva York, Mayo.

TOLEDO LLANCAQUEO, V., (2005). "Las fronteras indigenas de la globalización". En VVAA, Pueblos Indigenas y Democracia en América Latina. CLACSO.

VAN COTT, D. L., (2002). The Friendly Liquidation of the Past: The Politics of Diversity in Latin America. University of Pittsburg Press. 